\title{
María de los Ángeles Rodríguez Álvarez (2014), Yo, Gregorio Torres Quintero, Colima, Archivo Histórico del Municipio de Colima
}

\author{
Rosalia Menindez Martínez \\ Universidad Pedagógica Nacional, México \\ r_menindez@yahoo.com.mx
}

El libro nos ofrece una especial biografía en la que el entramado narrativo se teje a través de la voz del personaje central, Gregorio Torres Quintero. Sus cartas, libros, escritos periodísticos, artículos, cuadernos de notas, postales de viaje, y toda una amplia documentación oficial relativa a su ejercicio profesional como profesor y funcionario, así como una amplia gama de testimonios escritos, son recuperados por la autora para construir la biografía de este especial, interesante y destacado personaje del espacio educativo mexicano de finales del siglo XIX y principios del siglo XX, en un periodo en que el país transitaba de una sociedad de antiguo régimen a una sociedad con tintes de modernidad.

La biografía de un maestro normalista es portadora de valiosa información. François Dossel señala que una biografía "puede ser una manera de empezar a restituir una época con sus sueños y sus angustias", y Walter Benjamin habla de "hacer ver cómo la vida entera de un individuo está presente en una de sus obras, en uno de sus hechos [y] cómo en la vida está presente una época entera" (2007: 15). En este libro encontraremos parte de la memoria educativa, política, económica y cultural del momento en que el personaje vivió.

Gregorio Torres Quintero fue originario del estado de Colima. Maestro, egresado de la primera generación de alumnos de la Escuela Normal de la Ciudad de México, funcionario público, director de escuela, supervisor escolar, autor de libros de texto, articulista, director de revistas pedagógicas, poeta, cuentista, miembro de sociedades y colegios de profesores; todo esto es Torres Quintero, pero quizás lo más interesante de este maestro colimota es que traspasa el espacio de las aulas y de la escuela y se inserta en los espacios de la élite educativa porfiriana. Podemos decir que fue un hombre que vivió intensamente su vida profesional, convirtiéndola en el eje conductor de su propia vida: "Era un hombre que concebía al trabajo como uno de sus más preciados valores; con una inclinación marcada para la verdad y la humildad, con enorme aprecio a la discreción, la mesura en el hablar, caminar, 
vestir y comer" (p. 21). Por lo tanto, la mayor parte de las páginas del libro dan cuenta de su vida laboral, sin dejar de lado algunos aspectos de su vida personal.

El momento clave que dará inicio a una vida que trascenderá en el ámbito educativo está marcado por un maestro. El subtítulo del capítulo segundo indica el sentido de este capítulo: "Un maestro transformó mi niñez". En él, Torres Quintero "dice", en voz de la autora: "Ir a la escuela fue la primera experiencia que marcó mi vida" (p. 65). Efectivamente, para un niño que vivía en un estado pobre, como era Colima, que contaba con una escasa estructura educativa, y con padres de recursos limitados, el poder asistir a una escuela en la década de 1870 era un privilegio, pero sobre todo una gran oportunidad. Su primera experiencia educativa la tiene en una escuela lancasteriana como eran la mayoría en esa época; sus prácticas, saberes aprendidos y la vida escolar con su día a día se narran en este capítulo.

El segundo momento de importancia en la formación y futuro del personaje se presenta en el tercer capítulo, con su ingreso al Liceo de Varones de Colima, un establecimiento con un modelo educativo de influencia francesa, que Quintero se lo atribuye quizás a la influencia del francés Mathieu de Fossey. El momento político tiene ya a Porfirio Díaz en el escenario nacional, pero Manuel González ocupa la Presidencia de la República, de 1880 a 1884 . Su formación continúa delineándose de una especial manera: se trata de una escuela laica, moderna y de buen nivel académico. A lo largo del capítulo se narra nuevamente su experiencia como alumno y esto implica sus días de clase con sus materiales escolares, materias, profesores, libros, mobiliario, juegos y diversiones.

En 1883, ya en pleno Porfiriato, obtiene su título de preceptor de primer orden —es decir, de profesor- e inicia su vida laboral, la cual estará marcada por un continuo movimiento, siempre en ascenso, cambiando de puesto con sueldos muy modestos como correspondía a la paga de todo profesor. Un aspecto poco tratado en el libro, posiblemente por la falta de fuentes, es la vida personal del personaje; sin embargo, en este capítulo, en breves líneas, se menciona el inicio de un noviazgo que duró diez años; es decir, primero estuvo el trabajo y luego vendría el matrimonio.

Su primer trabajo lo obtiene a los diez y siete años como sinodal en un examen de titulación; en seguida, se le encomienda la escuela de primeras letras anexa al Liceo de Varones, y sigue como catedrático de matemáticas en el Liceo; más tarde es nombrado director de la Escuela de Niños de Manzanillo. A partir de una breve estancia en la escuela Cuauhtémoc obtiene experiencia como maestro, pero sobre todo logra mirar la situación y necesidades de la escuela; para esta década las escuelas presentaban grandes carencias y practicar el magisterio implicaba un compromiso con la comunidad, pero sobre todo con los niños. Todo este escenario nos presenta la autora en su capítulo cuarto.

Ahora bien, ¿cuál es el momento crucial en la vida académica de Torres Quintero? La respuesta se encuentra en el capítulo quinto, "La Escuela Normal de Profesores". 
En 1887, el gobierno de Porfirio Díaz lanza una convocatoria a fin de que jóvenes de todo el país sean becados para estudiar en la recién inaugurada Escuela Nacional Normal de Profesores de la Ciudad de México. Dos becas se otorgan al estado de Colima y una de ellas la obtiene Torres Quintero. Estos apoyos son parte de un proyecto más amplio del régimen de Díaz y que su ministro Baranda atenderá de manera especial: la modernización del sistema educativo con miras a una expansión nacional, en especial a través de la formación de maestros.

Al estudiar en la Escuela Normal de la Ciudad de México, Torres Quintero ingresa al proyecto porfirista para el magisterio, parte integral del proyecto de la modernidad educativa que ha sido pensado y planeado por un cuerpo de maestros y directivos de la talla de Ignacio Manuel Altamirano, Justo Sierra, Manuel Flores, Miguel Schulz, Miguel Serrano, Manuel Cervantes Imaz, Carlos A. Carrillo, entre otros. Los primeros jóvenes formados en la Escuela Normal regresarán a sus estados para ser maestros, directivos o supervisores, encargados de implantar una educación liberal con nuevos métodos, libros y currículos renovados. Torres Quintero hará este camino en un primer momento; más tarde lo rebasará.

En el capítulo sexto se narra "El retorno a casa". Ya como maestro normalista, Torres Quintero pondrá en práctica los saberes aprendidos en la Normal: difunde el pensamiento moderno para la educación a través de su práctica como maestro y funcionario, pero más importante se inicia como escritor. Con el propósito de mejorar su labor como maestro, realiza traducciones de textos en francés, posteriormente publica artículos con temas pedagógicos, y más tarde se inicia como autor de libros de texto y libros escolares.

En el capítulo séptimo se narra un momento fundamental en su vida profesional: un ofrecimiento de trabajo en la Ciudad de México como oficial segundo interino de la Dirección Primaria, en lugar de Andrés Oscoy. Quien se lo ofrece es el maestro Luis E. Ruiz, director de Instrucción Primaria, y a partir de ese empleo sus vínculos con la élite educativa lo llevarán a ocupar diversos puestos directivos. Sin embargo, Torres Quintero nunca dejará de publicar y de escribir artículos para las revistas donde colaboró y fue director, como La Educación Moderna, La Educación Contemporánea y La Enseñanza Primaria. La publicación de libros de texto será otro de sus compromisos con la educación; su producción es amplia, y quizá su obra más conocida, que le dio un lugar en el espacio de la historia de la pedagogía, fue su Método onomatopéyico, publicado en 1904.

A partir del capítulo octavo se narran los momentos que tendrá la vida del personaje tras la caída del régimen de Porfirio Díaz. Maestro y hombre del Porfiriato intentará seguir en su labor como educador, aunque los vientos hayan cambiado y ahora apunten a la Revolución. Aun cuando ya era un hombre muy reconocido como pedagogo, y funcionario, esto no fue suficiente y, en 1911, se lanzó a la gubernatura del estado de Colima pero no ganó. 
Su labor como autor de libros de texto y como autor de artículos pedagógicos continuó y su producción fue abundante. Se insertó de alguna manera en los espacios que dieron los gobiernos revolucionarios y posrevolucionarios; ocupó cargos en Yucatán y estableció vínculos académicos en varias partes del país; su aportación en estos años fue el libro La instrucción rudimentaria en la República. Fue testigo activo de la creación de la nueva Secretaría de Educación Pública, a cargo de José Vasconcelos, quien le invitó a trabajar en ella. A finales de 1921 fue nombrado Consejero Técnico de Educación Primaria y Normal del Departamento Escolar; ocupó el puesto hasta el 1 de marzo de 1923, momento en que se jubiló.

Finalmente, algo que alimentó sus últimos años fueron sus viajes: primero a Estados Unidos y, ya jubilado, por Europa, Asia y África, entre 1926 y 1928.

Murió el 28 de enero de 1934.

En este libro encontramos un especial tratamiento de la biografía. A lo largo de sus 613 páginas el lector podrá encontrar una biografía novedosa, novelada, pero con un importante respaldo documental basado en una diversidad de fuentes (referidas en 934 citas) y con una amplia base bibliográfica y de material hemerográfico. La autora consultó páginas electrónicas, documentación obtenida en 19 archivos y 19 revistas de finales del siglo XIX y primeras décadas del siglo XX, además de los 61 libros de autoría de Gregorio Torres Quintero con sus diversas ediciones.

A partir del estudio minucioso de este rico y abundante material, la autora puede escribir una biografía que es soportada por fuentes de primera mano, que bien puede ser un material de consulta obligado para todo aquel investigador interesado en los siguientes temas y mucho más: el magisterio en la época porfirista y revolucionaria, en la escuela normal, en los libros de texto, o en la historia de los pedagogos mexicanos. No sólo es un texto para investigadores, también lo es para maestros, estudiantes y todo aquel interesado en adentrarse en la historia de la vida educativa del país de fines del siglo XIX y principios del siglo XX.

Es un libro que nos adentra en la vida de un maestro normalista, un maestro que formó parte de la élite educativa del Porfiriato, élite que construyó el proyecto educativo del siglo Xx. En ese periodo, los normalistas ganaron un espacio y su presencia tendría efectos durante todo el siglo que iniciaba. Estos intelectuales educativos fueron transmisores de una propuesta pedagógica y educativa, de un pensamiento, y de una serie de ideas con todo lo que ello implicó para la formación de las mentes de sus jóvenes alumnos. 